\title{
High-resolution anorectal manometry in children with functional constipation: a single-centre experience before and after treatment
}

\author{
Mortada El-Shabrawi ${ }^{1}$, Hind M. Hanafi' ${ }^{2}$, Manal M.A.H. Abdelgawad², Fetouh Hassanin ${ }^{3}$, Aml A.A. Mahfouze ${ }^{2}$, \\ Ahmed F.M. Khalil2, Saeed Elsayed Elsawey² \\ ${ }^{1}$ Department of Pediatrics, Faculty of Medicine, Cairo University, Cairo, Egypt \\ ${ }^{2}$ Department of Pediatric, Faculty of Medicine, Alexandria University, Alexandria, Egypt \\ ${ }^{3}$ Department of Clinical Pharmacy, Misr International University, Cairo, Egypt
}

Gastroenterology Rev 2018; 13 (4): 305-312

DOI: https://doi.org/10.5114/pg.2018.79810

Key words: manometry, constipation, paediatric, Egypt.

Address for correspondence: Fetouh Saad Hassanin, Department of Clinical Pharmacy, Misr International University, 28 km Cairo Ismailia Desert Road, 11882 Cairo, Egypt, phone: +20 201006756257, e-mail: fhassanin@aim.com

\begin{abstract}
Introduction: Constipation is a common disorder among children, and most of the cases are functional in aetiology. Few studies have reported the manometric data of normal and constipated children.

Aim: To evaluate the manometric parameters in children with functional constipation and to assess any possible changes in these parameters after treatment.

Material and methods: A prospective descriptive study was conducted at a single centre, enrolling 50 children diagnosed with functional constipation based on Rome IV criteria. Their age ranged from 6 to 14 years with a mean of $7.31 \pm 1.72$ years. High-resolution manometry was performed on all children at the initial presentation and after six months of treatment.

Results: The studied children showed markedly abnormal rectal sensation parameters (increased first sensation, first urge, intense urge, and maximum tolerable volume) during rectal balloon distension. These parameters were even higher in children with stool incontinence $(p=0.005)$. Manometric data after 6 months of treatment showed that the resting and squeeze pressures were increased when compared to pre-treatment recordings; however, both were statistically insignificant $(p=0.474$ and $p=0.155$, respectively). Abnormalities in rectal sensations and the manometric parameters reached near normal values following treatment.

Conclusions: Anorectal manometry is sensitive in predicting improvement in patient condition even before complete clinical cure, and it has a prognostic role in the management of childhood constipation. More research is still needed before recommending anorectal manometry as a routine diagnostic or prognostic tool in paediatric constipation management.
\end{abstract}

\section{Introduction}

Childhood constipation is a common disorder among children all over the world [1]. The prevalence in children varies widely, ranging from $0.7 \%$ to $29.6 \%$ [2]. Between $3 \%$ and $10 \%$ of visits to primary health care centres and up to $25 \%$ of referrals to paediatric gastroenterologists are related to constipation [3]. The aetiology of chronic constipation in children is multifactorial, but the great majority of cases are functional constipation. Organic causes include anorectal structural abnormalities, neurogenic disorders, drugs or metabolic disorders, and connective tissue disorders. The pathogenesis of functional constipation is still unclear, but it is mostly associated with stool retention that leads to intentional with holding after experiencing a painful bowel motion [2]. Untreated, longstanding functional constipation leads to excessive faecal impaction and soiling. It may also be associated with chronic abdominal pain, anorexia, or anal fissures. Children may also experience some urinary problems including dysuria, recurrent urinary tract infections, and urinary incontinence [4]. Rome IV criteria represent the widely-accepted method for diagnosis of functional constipation in the paediatric age group [5]. The management of functional constipation is usually challenging, and relapses are common [6]. Laxatives, dietary interventions, and behavioural modifications are the cornerstones of treatment. Large doses of oral and/or rectal laxatives are used initially for faecal disimpaction [7-9]. After disimpaction, 
laxatives are used for several months and sometimes years (maintenance phase) [10]. Anorectal manometry (ARM) is the most frequently performed motility study in children. Anorectal manometry is an important tool to assess anorectal sensations, pressure changes, and rectal compliance. It also evaluates anal sphincter function and anorectal reflexes [11]. Therefore, ARM is beneficial to assess anorectal function in children with chronic constipation, especially if they are laxative dependent or poor responders to treatment. Also, it helps in the assessment of sphincter function as well as anorectal sensation in children with faecal incontinence. The ARM also evaluates the recto-anal inhibitory reflex, which is absent in Hirschsprung's disease and internal anal sphincter achalasia, and thus confirms the diagnosis of functional constipation in doubtful cases [12]. High-resolution manometry (HRM) involves the use of a larger number of pressure sensors compared to the conventional devices and thus provides more pressure recordings and easier interpretation [13]. Although conventional anorectal manometry parameters have been evaluated in children with chronic functional constipation in several studies [14-16], modern HRM parameters still need to be further evaluated. Studying the manometric findings in constipated children may be of benefit in understanding the pathophysiological changes in defecation dynamics, which probably occur due to chronic rectal distension and dilatation.

\section{Aim}

We conducted this prospective study to evaluate the manometric parameters in children with functional constipation and to assess any possible changes in these parameters after treatment at a single centre.

\section{Material and methods}

A prospective descriptive study was conducted between February and September 2017 at the Gastroenterology Unit, Alexandria University Children Hospital, Alexandria, Egypt. The study included 50 children diagnosed with functional constipation based on Rome IV criteria, aged between 6 and 14 years, who were otherwise healthy. Children with anorectal structural defects, Hirschsprung's disease, neuropathies, metabolic disorders, and connective tissue disorders were excluded. Children using drugs that may have affected gastrointestinal motility were also excluded. Written informed consent was obtained from the parents of all participating children, and the study design was approved by the local Ethics Committee.

All children were submitted to detailed history taking, including clinical symptoms with probable precipitating factors, stool characteristics (stool diary), and family history of chronic constipation. This was followed by physical examination, digital rectal examination (DRE), and anorectal manometry. Other imaging studies or laboratory investigations to exclude organic causes of constipation were only requested as appropriate. After diagnosis, treatment was initiated according the clinical guidelines published for management of functional constipation $[1,6]$.

\section{Treatment protocol}

A. Education: The pathophysiology of functional constipation and faecal incontinence was explained with the help of diagrams. Caregivers were assured about the safety of long-term laxative use. The importance of compliance was also highlighted to them and to the patients.

B. Disimpaction phase: Children with faecal impaction were given high-dose laxatives in the form of a combination of lactulose syrup in a dose of $3 \mathrm{ml} / \mathrm{kg} /$ day and a stimulant laxative (sodium picosulphate; 2.5-20 mg/day. We used a drop formulation; each $1 \mathrm{ml}$ contained $7.5 \mathrm{mg}$ ). Parents were asked to return in 5-7 days to evaluate the success of the disimpaction.

C. Maintenance phase:

- Behavioural modifications: The children were asked to sit on the toilet shortly after a meal, for 5 to $10 \mathrm{~min}$, two to three times per day, and they were asked to avoid intentional stool withholding. Caregivers were advised to deal with child adherence to this program with positive reinforcement such as encouragement and reward rather than criticism or punishment, and to keep a child-friendly stool diary that includes bowel movements, use of medications, abdominal pain, episodes of faecal incontinence, and any other symptoms.

- Diet modifications: Caregivers were advised to achieve adequate daily fluid intake and adequate daily fibre intake in the form of vegetables, fruit, and whole grain cereals and bread.

- Maintenance laxatives: Lactulose was used as a first-line maintenance in a dose of 1-2 $\mathrm{ml} /$ $\mathrm{kg} /$ day in two to three divided doses. Stimulant laxatives (sodium picosulphate $2.5-20 \mathrm{mg} /$ day) and/or mineral oil (paraffin oil $1-3 \mathrm{ml} / \mathrm{kg}$ / day) were used as an additional maintenance laxative if needed. Laxative doses were adjusted according to the clinical response to achieve a stool frequency of two to three soft bowel motions per day. Maintenance laxatives were continued for at least 4 months. If the patient's symptoms were stabilised for a duration of at 
least 1 month, then slow gradual weaning from laxatives was considered.

Anorectal manometry was performed to all children at the initial presentation, and a follow-up manometry procedure was performed again after 6 months of treatment. Changes in manometric parameters were reported using the same protocol used in the initial anorectal manometry. All the procedures were performed by the same operator.

\section{Manometry procedure}

Solar GI HRAM device (High Resolution Anorectal Manometry) manufactured by Medical Measurements Simple (MMS), Enschede, Netherlands was used in all cases. A reusable water-perfused HRM catheter with 20+1 pressure channel with latex free inflation balloon attached to the distal segment (manufactured by Mui Scientific, Ontario, Canada) was used. An enema was given if stools were detected on a digital rectal examination, and at least 30 min were allowed from enema insertion to probe placement. No sedation was given. The patient was placed in the left lateral position with knees and hips flexed at $90^{\circ}$. The lubricated probe was gently inserted into the rectum.

\section{HR-ARM parameters and interpretations}

After probe placement, a run-in period of approximately five minutes was allowed, to give the patient time to relax such that anal sphincter tone returned to basal levels. Anal resting pressure was generally measured for $20 \mathrm{~s}$. The child was then asked to squeeze the anus for as long as possible, for a maximum of $30 \mathrm{~s}$, followed by a one-minute rest. Recto-anal inhibitory reflex (RAIR) was then evaluated. Air was injected rapidly to inflate the rectal balloon and then the balloon was immediately deflated within 3-5 s. Repeated insufflations of the balloon with a $10 \mathrm{ml}$ increment in volume each time were performed until a reflex relaxation of the internal anal sphincter was obtained. The minimum amount of air required to elicit an IAS relaxation was determined. If the RAIR was absent during rectal balloon distension, the case would be excluded. Rectal sensations were then obtained. The rectal balloon was distended with air in increments of $10 \mathrm{ml}$ and maintained for at least $30 \mathrm{~s}$ until the patient reported a sensation of fullness or bloating or gas (first sensation). Thereafter, the balloon was distended with increments of $20 \mathrm{ml} \mathrm{up}$ to a maximum volume of $400 \mathrm{ml}$. Patients were asked to report the following sensations: First feeling of rectal content (first sensation), the first sensation of urgency for defecation (first urge), a steady need to defecate (intense urge), and the painful lasting urge to defecate (max tolerable volume). These distensions were termi- nated earlier if the maximum tolerable volume of the patient was reached.

\section{Statistical analysis}

Data were analysed using SPSS software package version 20.0 (Armonk, NY: IBM Corp). Qualitative data were described using numbers and percentages. Quantitative data were described using range (minimum and maximum), mean, standard deviation, and median. The significance of the obtained results was judged at the $5 \%$ level. McNemar test, paired $t$-test, Wilcoxon signed ranks test, Mann Whitney test, and Spearman coefficient were used.

\section{Results}

Fifty children with functional constipation were enrolled during the period of the study. Their ages ranged between 6 and 14 years (mean: $7.31 \pm 1.72$ years). Fifty-six per cent were girls and $56 \%$ were from urban areas. The majority of the studied children (86\%) were of low to middle socioeconomic status and belonged to mothers with low to intermediate level of education. The mean duration of complaints before presentation to the gastroenterology unit was $20.38 \pm 11$ months (3- 48 months). Low dietary fibre intake, urge postponing when in public places, especially schools, were identified in $72 \%$ and $68 \%$ of cases, respectively. There was a familial tendency for chronic constipation in $38 \%$ of cases. Clinical presentations and defecation characteristics of the studied children are shown in Tables I and II, respectively.

\section{Initial manometric data}

The mean anal canal length was $2.84 \pm 0.47 \mathrm{~cm}$ $(2.0-3.90 \mathrm{~cm})$. The studied children showed markedly abnormal rectal sensation parameters (increased first sensation, first urge, intense urge, and maximum tol-

Table I. Clinical presentation among constipated children

\begin{tabular}{lcc} 
Clinical presentation & N & \% \\
\hline Infrequent defecations & 39 & 92 \\
\hline Abdominal pain & 30 & 60.0 \\
\hline Anorexia & 23 & 46.0 \\
\hline Abdominal distension & 19 & 38.0 \\
\hline Faecal incontinence & 9 & 18.0 \\
\hline Bleeding per rectum & 18 & 36 \\
\hline Urinary symptoms & 42 & 84
\end{tabular}


Table II. Stool characteristics among constipated children

\begin{tabular}{lcc} 
Stool characteristics & N & $\%$ \\
\hline Infrequent defecations & 41 & 92 \\
\hline Bulky stool & 17 & 34.0 \\
\hline $\begin{array}{l}\text { Manual manoeuvres to help } \\
\text { defecations }\end{array}$ & 34 & 68.0 \\
\hline $\begin{array}{l}\text { Stool withholding behaviour } \\
\text { Predominant type of stool according to Bristol stool form scale: }\end{array}$ & 19 & 38 \\
\hline $\begin{array}{l}\text { Type 1 } \\
\text { Type 2 }\end{array}$ & 22 & 44 \\
\hline Type 3 & 9 & 18
\end{tabular}

erable volume) during rectal balloon distension. These values were even higher in children with stool incontinence than in those children who had never experienced stool incontinence. First urge sensation was significantly higher among children with stool incontinence. There was a statistically significant positive correlation between the duration of constipation and the intense urge and the maximum tolerable volume. There were also statistically significant inverse correlations between stool frequency and the rectal sensation parameters. Children with higher values for rectal sensations had longer duration of symptoms and tended to defecate less often per week (Tables III-VI).

\section{Manometric data after six months of treatment}

The resting pressure and the squeeze pressure were increased when compared to initial pre-treatment recordings; however, both were statistically insignificant ( $p=0.474$ and $p=0.155$, respectively). All rectal sensation parameters were significantly decreased compared to initial parameters (Table VII).

\section{Discussion}

Functional constipation is a common problem in children worldwide and an emerging public health problem. There are great variations regarding the epidemiologic data, pathophysiology, and anorectal functional abnormalities reported in children with functional constipation [17]. Low fibre intake and the habit of urge postponing when in public places, especially in school, were the most commonly reported risk factors for constipation in the current study. The protective role of fibre against constipation is supposedly related to adding bulk and water content to the stool; this can make the stool softer and easier to pass. This was consistent with
Table III. Initial manometric findings in children with chronic constipation

\begin{tabular}{|c|c|}
\hline Parameter & Values \\
\hline \multicolumn{2}{|c|}{ Resting pressure [mm Hg]: } \\
\hline Min.-max. & $15.40-76.50$ \\
\hline Mean \pm SD & $54.82 \pm 18.90$ \\
\hline Median & 49.50 \\
\hline \multicolumn{2}{|c|}{ Squeeze pressure [mm Hg]: } \\
\hline Min.-max. & $67.80-200.0$ \\
\hline Mean \pm SD & $149.13 \pm 40.16$ \\
\hline Median & 150.30 \\
\hline \multicolumn{2}{|c|}{ First sensation [ml]: } \\
\hline Min.-max. & 10.0-120.0 \\
\hline Mean \pm SD & $43.0 \pm 27.87$ \\
\hline Median & 40.0 \\
\hline \multicolumn{2}{|l|}{ First urge $[\mathrm{ml}]$ : } \\
\hline Min.-max. & $20.0-200.0$ \\
\hline Mean \pm SD & $122.80 \pm 38.51$ \\
\hline Median & 100.0 \\
\hline \multicolumn{2}{|c|}{ Intense urge [ml]: } \\
\hline Min.-max. & $110.0-400.0$ \\
\hline Mean \pm SD & $217.0 \pm 72.77$ \\
\hline Median & 195.0 \\
\hline \multicolumn{2}{|c|}{ Maximum tolerable volume $[\mathrm{mll}$ : } \\
\hline Min.-max. & $140.0-400.0$ \\
\hline Mean \pm SD & $248.0 \pm 72.90$ \\
\hline Median & 225.0 \\
\hline
\end{tabular}

several studies that reported a low-fibre diet as an important contributing factor for childhood constipation [18-22]. Urge postponing in public places was attributed in our cases to the lack of clean public bathrooms at schools and shyness in some cases. This was similar to Kocaay et al. and Felt et al., who found that a large proportion of school children do not use school toilets to defecate $[23,24]$. Common presenting symptoms were abdominal pain and anorexia in $78 \%$ and $60 \%$, respectively. Loening-Baucke and Swidsinski, reported constipation as the most common cause of chronic abdominal pain in children [25]. Faecal incontinence was another common presenting symptom as seen in $38 \%$ of our cases. Some authors have reported a prevalence 
Table IV. Comparison of rectal sensations between constipated children with and without faecal incontinence

\begin{tabular}{|c|c|c|c|c|}
\hline Rectal sensation parameter & $\begin{array}{l}\text { Constipated children without } \\
\text { faecal incontinence }(n=31)\end{array}$ & $\begin{array}{l}\text { Constipated children with faecal } \\
\text { incontinence }(n=19)\end{array}$ & $U$ & $P$-value \\
\hline \multicolumn{3}{|l|}{ First sensation: } & 148.00 & 0.177 \\
\hline Min.-max. & 20.0-90.0 & $10.0-120.0$ & & \\
\hline Mean \pm SD & $36.96 \pm 17.95$ & $52.94 \pm 33.12$ & & \\
\hline Median & 40.0 & 40.0 & & \\
\hline \multicolumn{3}{|l|}{ First urge: } & $92.50^{*}$ & $0.005^{*}$ \\
\hline Min.-max. & 20.0-180.0 & $70.0-200.0$ & & \\
\hline Mean \pm SD & $111.30 \pm 35.81$ & $152.94 \pm 38.22$ & & \\
\hline Median & 90.0 & 130.0 & & \\
\hline \multicolumn{3}{|l|}{ Intense urge: } & 131.50 & 0.079 \\
\hline Min.-max. & $110.0-400.0$ & $150.0-400.0$ & & \\
\hline Mean \pm SD & $207.39 \pm 71.49$ & $246.47 \pm 69.01$ & & \\
\hline Median & 190.0 & 240.0 & & \\
\hline \multicolumn{3}{|l|}{ Maximum tolerable volume: } & 127.50 & 0.062 \\
\hline Min.-max. & $140.0-400.0$ & $160.0-400.0$ & & \\
\hline Mean \pm SD & $238.70 \pm 68.58$ & $278.82 \pm 68.73$ & & \\
\hline Median & 220.0 & 280.0 & & \\
\hline
\end{tabular}

Table V. Correlation between duration of symptoms and rectal sensations $(n=50)$

\begin{tabular}{lcc} 
Rectal sensations & \multicolumn{2}{c}{ Duration of symptoms [months] } \\
\cline { 2 - 3 } & $\boldsymbol{r}_{\mathrm{s}}$ & $\boldsymbol{P}$-value \\
\hline First sensation & 0.004 & 0.980 \\
\hline First urge & 0.136 & 0.404 \\
\hline Intense urge & $0.326^{*}$ & $0.040^{*}$ \\
\hline Maximum tolerable volume & $0.409^{*}$ & $0.009^{*}$ \\
$r_{s}-$ Spearman coefficient. *Statistically significant at $p \leq 0.05$.
\end{tabular}

of faecal incontinence among constipated children ranging between $16 \%$ and $90 \%$ [3, 23, 26]. Sometimes it can be mistaken by caregivers as having diarrhoea, and they consequently seek medical advice for chronic diarrhoea, and this probably makes the diagnosis challenging. Manometric testing of the anorectal region gives beneficial data about anorectal function. However, it is not commonly used, and standardisation is still lacking. Although normal values for anorectal manometry have been published in adults, including high-resolution manometry, there have been few studies reporting manometric data of normal and constipated children.
Table VI. Correlation between stool frequency (per week) and rectal sensations ( $n=50)$

\begin{tabular}{lcc} 
Rectal sensations & \multicolumn{2}{c}{ Stool frequency (per week) } \\
\cline { 2 - 3 } & $r_{s}$ & $P$-value \\
\hline First sensation & $-0.319^{*}$ & $0.045^{*}$ \\
\hline First urge & $-0.326^{*}$ & $0.040^{*}$ \\
\hline Intense urge & $-0.335^{*}$ & $0.034^{*}$ \\
\hline Maximum tolerable volume & $-0.376^{*}$ & $0.017^{*}$ \\
$r_{s}-$ Spearman coefficient. *Statistically significant at $p \leq 0.05$.
\end{tabular}

Anal canal length, mean resting pressure, maximum squeeze pressure, and anorectal sensations were evaluated in the current study and compared before and after medical treatment. In our study, the mean values of resting anal pressure and maximum anal squeeze pressure were similar to the reported values in healthy children. This was in agreement with Fathy et al. [27], who described anorectal functional abnormalities in Egyptian children with chronic functional constipation, and other international authors who recorded a normal anal resting tone in constipated children and did not find a significant difference between constipated children 
Table VII. Follow-up manometric findings

\begin{tabular}{|c|c|c|c|}
\hline \multirow[t]{2}{*}{ Parameter } & \multicolumn{2}{|c|}{ Anorectal manometry } & \multirow[t]{2}{*}{$P$-value } \\
\hline & Initial & Follow-up & \\
\hline Resting [mm Hg]: & & & ${ }^{w x} p=0.474$ \\
\hline Min.--max. & $15.40-76.50$ & $24.40-86.50$ & \\
\hline Mean \pm SD & $54.82 \pm 18.90$ & $59.94 \pm 17.70$ & \\
\hline Median & 49.50 & 56.20 & \\
\hline Squeeze [mm Hg]: & & & $w^{*} p=0.155$ \\
\hline Min.--max. & $67.80-200.0$ & $58.80-225.0$ & \\
\hline Mean \pm SD & $149.13 \pm 40.16$ & $157.45 \pm 43.58$ & \\
\hline Median & 150.30 & 155.0 & \\
\hline First sensation [ml]: & & & $w_{x} p=0.002^{*}$ \\
\hline Min.--max. & $10.0-120.0$ & $10.0-80.0$ & \\
\hline Mean \pm SD & $43.0 \pm 27.87$ & $26.80 \pm 12.53$ & \\
\hline Median & 40.0 & 30.0 & \\
\hline First urge [ml]: & & & $w_{x} p=0.001^{*}$ \\
\hline Min.--max. & $20.0-200.0$ & $40.0-170.0$ & \\
\hline Mean \pm SD & $122.80 \pm 38.51$ & $82.80 \pm 32.64$ & \\
\hline Median & 100.0 & 80.0 & \\
\hline Intense urge [ml]: & & & ${ }^{w_{x}} p<0.001^{*}$ \\
\hline Min.-max. & $110.0-400.0$ & $70.0-250.0$ & \\
\hline Mean \pm SD & $217.0 \pm 72.77$ & $145.0 \pm 45.77$ & \\
\hline Median & 195.0 & 150.0 & \\
\hline Maximum tolerable volume [ml]: & & & ${ }^{w_{x}} p<0.001^{*}$ \\
\hline Min.--max. & $140.0-400.0$ & $100.0-280.0$ & \\
\hline Mean \pm SD & $248.0 \pm 72.90$ & $173.40 \pm 47.41$ & \\
\hline Median & 225.0 & 170.0 & \\
\hline
\end{tabular}

and healthy controls [28-31]. The presence of intact rectoanal inhibitory reflex (RAIR) excludes Hirschsprung's disease, which is a very important value for anorectal manometry in children. In the present study, all children had intact RAIR. However, some studies have reported false positive results in children with functional constipation. It seems that marked rectal dilatation (megarectum) in some children with prolonged functional constipation may interfere with the reflex [12]. The studied children showed markedly abnormal rectal sensations (increased first sensation, increased first urge, and increased intense urge). Also, they tolerated a markedly high maximum tolerable volume. This is in agreement with many authors, who recorded abnormally high rectal sensations in constipated children [27, 28, 32-36]. These values for rectal sensations among constipated children were higher in comparison with the values reported from several studies evaluating the rectal sensations among healthy children [28-30]. The aetiology of the reported abnormal rectal sensations is not fully understood. It may represent a primary problem or may simply be secondary to the megarectum. In the present work, following medical treatment for 6 months, all rectal sensation parameters were significantly decreased and were approaching the reported values in normal children. This signifies the effect of treatment on res- 
toration of normal sensation in constipated children and may support the theory that abnormal sensations are attributed to chronic rectal distention. The current study compared the rectal sensations (first sensation, first urge, intense urge, and the maximum tolerable volume) among constipated children with and without faecal incontinence. All rectal sensation parameters were higher in children with incontinence, especially the first urge $(p=0.005)$. It seems that children with faecal incontinence may have more rectal dilatation, which may explain the their markedly abnormal rectal sensations. Data discussing this observation are still lacking, and more studies are needed in order to reach a valid conclusion. In the present study, there was an inverse correlation between stool frequency and rectal sensations among our studied children. Children with higher values for rectal sensations tended to defecate less often per week. The current work also showed a positive correlation between duration of constipation and the maximum tolerable volume. Those children who complained for a more prolonged duration tended to have a higher maximum tolerable volume. This was similar to Martinac et al., who reported an inverse correlation between the number of defecations and the first sensation [37]. The prolonged retention of stool results in increasing rectal dilatation and will cause higher rectal sensations, which will progressively delay the perception of the need for defecations and infrequent bowel movements. On the other hand, Borowitz et al. did not find a correlation between defecation frequency and rectal sensations [38]. The abnormalities in rectal sensations (first sensation, urge to defecate, intense urge, and maximum tolerable volume) and the change in these manometric parameters to near normal values following the treatment reflect the success of proper treatment on restoration of rectal sensations. Further study of the anorectal manometric functions in children who successfully recovered from functional constipation are needed to evaluate if these parameters would normalise after treatment. The current work also reflects the sensitivity of anorectal manometry in predicting the improvement in patient condition even before complete clinical cure. These factors, alongside the good clinical correlation, probably suggest a prognostic rule for anorectal manometry in childhood constipation. However, this may not be easy due to technical difficulties because the anorectal manometry device is not available at many centres. More research is still needed before recommending anorectal manometry as a routine diagnostic or prognostic tool in constipation management.

\section{Conflict of interest}

The authors declare no conflict of interest.

\section{References}

1. Tabbers MM, DiLorenzo C, Berger MY, et al. Evaluation and treatment of functional constipation in infants and children: evidence-based recommendations from ESPGHAN and NASPGHAN. J Pediatr Gastroenterol Nutrition 2014; 58: 258-74.

2. Rajindrajith S, Devanarayana NM. Constipation in children: novel insight into epidemiology, pathophysiology and management. J Neurogastroenterol Motility 2011; 17: 35-47.

3. Chang SH, Park KY, Kang SK, et al. Prevalence, clinical characteristics, and management of functional constipation at pediatric gastroenterology clinics. J Korean Med Sci 2013; 28: 1356-61.

4. Dehghani SM, Kulouee N, Honar N, et al. Clinical manifestations among children with chronic functional constipation. Middle East J Dig Dis 2015; 7: 31-5.

5. Hyams JS, Di Lorenzo C, Saps M, et al. Functional disorders: children and adolescents. Gastroenterology 2016; pii: S00165085(16)00181-5. doi: 10.1053/j.gastro.2016.02.015.

6. Biggs WS, Dery WH. Evaluation and treatment of constipation in infants and children. Am Family Phys 2006; 73: 469-77.

7. Loening-Baucke V. Polyethylene glycol without electrolytes for children with constipation and encopresis. J Pediatr Gastroenterol Nutr 2002; 34: 372-7.

8. Bekkali NL, van den Berg MM, Dijkgraaf MG, et al. Rectal fecal impaction treatment in childhood constipation: enemas versus high doses oral PEG. Pediatrics 2009; 124: e1108-15.

9. Miller MK, Dowd MD, Friesen CA, Walsh-Kelly CM. A randomized trial of enema versus polyethylene glycol 3350 for fecal disimpaction in children presenting to an emergency department. Pediatr Emergency Care 2012; 28: 115-9.

10. Koppen IJN, Lammers LA, Benninga MA, Tabbers MM. Management of functional constipation in children: therapy in practice. Paediatr Drugs 2015; 17: 349-60.

11. Lee TH, Bharucha AE. How to perform and interpret a high-resolution anorectal manometry test. J Neurogastroenterol Motil 2016; 22: 46-59.

12. Hong J. Clinical applications of gastrointestinal manometry in children. Pediatr Gastroenterol Hepatol Nutrition 2014; 17: 23-30.

13. Banasiuk M, Banaszkiewicz A, Dziekiewicz M, et al. Values from three-dimensional high-resolution anorectal manometry analysis of children without lower gastrointestinal symptoms. Clin Gastroenterol Hepatol 2016; 14: 993-1000.e3.

14. Noviello C, Cobellis G, Papparella A, et al. Role of anorectal manometry in children with severe constipation. Colorectal Dis 2009; 11: 480-4.

15. Liu TT, Chen CL, Yi CH. Anorectal manometry in patients with chronic constipation: a single-center experience. Hepatogastroenterology 2008; 55: 426-9.

16. Loening-Baucke VA. Abnormal rectoanal function in children recovered from chronic constipation and encopresis. Gastroenterology 1984; 87: 1299-304.

17. Rajindrajith S, Devanarayana NM. Constipation in children: novel insight into epidemiology, pathophysiology and management. J Neurogastroenterol Motil 2011; 17: 35-47.

18. de Araujo Sant'Anna AM, Calcado AC. Constipation in schoolaged children at public schools in Rio de Janeiro, Brazil. J Pediatr Gastroenterol Nutr 1999; 29: 190-3. 
19. Morais MB, Vitolo MR, Aguirre AN, Fagundes-Neto U. Measurement of low dietary fiber intake as a risk factor for chronic constipation in children. J Pediatr Gastroenterol Nutr 1999; 29: 132-5.

20. Ip KS, Lee WT, Chan JS, Young BW. A community-based study of the prevalence of constipation in young children and the role of dietary fibre. Hong Kong Med J 2005; 11: 431-6.

21. Markland AD, Palsson O, Goode PS, et al. Association of low dietary intake of fiber and liquids with constipation: evidence from the National Health and Nutrition Examination Survey (NHANES). Am J Gastroenterol 2013; 108: 796-803.

22. Roma E, Adamidis D, Nikolara R, et al. Diet and chronic constipation in children: the role of fiber. J Pediatr Gastroenterol Nutr 1999; 28: 169-74.

23. Kocaay P, Egritas O, Dalgic B. Normal defecation pattern, frequency of constipation and factors related to constipation in Turkish children 0-6 years old. Turk J Gastroenterol 2011; 22 369-75.

24. Felt B, Wise CG, Olson A, et al. Guideline for the management of pediatric idiopathic constipation and soiling. Multidisciplinary team from the University of Michigan Medical Center in Ann Arbor. Arch Pediatr Adolescent Med 1999; 153: 380-5.

25. Loening-Baucke V, Swidsinski A. Constipation is the most frequent cause of chronic abdominal pain in children. Open Pediatr Med J 2008; 2: 16-20.

26. Loening-Baucke V. Prevalence rates for constipation and faecal and urinary incontinence. Arch Dis Childhood 2007; 92: 486-9.

27. Fathy A, Megahed A, Barakat T, Abdalla AF. Anorectal functional abnormalities in Egyptian children with chronic functional constipation. Arab J Gastroenterol 2013; 14: 6-9.

28. Banasiuk M, Banaszkiewicz A, Albrecht P. PP-9 normal values of $3 \mathrm{D}$ high-resolution anorectal manometry in chidren. J Pediatr Gastroenterol Nutr 2015; 61: 523-4.

29. Kumar S, Ramadan S, Gupta V, et al. Manometric tests of anorectal function in 90 healthy children: a clinical study from Kuwait. J Pediatr Surg 2009; 44: 1786-90.

30. Nurko S, Garcia-Aranda JA, Guerrero VY, Worona LB. Treatment of intractable constipation in children: experience with cisapride. J Pediatr Gastroenterol Nutr 1996; 22: 38-44.

31. Turco R, Alessandrella A, Pozziello A, et al. High resolution anorectal manometry in children with functional constipation with or without fecal incontinence. Dig Liv Dis 2016; 48: e250.

32. Hou XY, Wang LY, Wang WL, et al. Clinical significance of detection of internal anal sphincter in children with functional constipation. Chin J Gastrointest Surg 2011; 14: 753-5.

33. Li ZH, Dong M, Wang ZF. Functional constipation in children: investigation and management of anorectal motility. World J Pediatr 2008; 4: 45-8.

34. Loening-Baucke V. Factors determining outcome in children with chronic constipation and faecal soiling. Gut 1989; 30 999-1006.

35. Benninga MA, Wijers OB, van der Hoeven CW, et al. Manometry, profilometry, and endosonography: normal physiology and anatomy of the anal canal in healthy children. J Pediatr Gastroenterol Nutr 1994; 18: 68-77.

36. van den Berg MM, Voskuijl WP, Boeckxstaens GE, Benninga MA. Rectal compliance and rectal sensation in constipated adolescents, recovered adolescents and healthy volunteers. Gut 2008; 57: 599-603.

37. Martinac $M$, Ebling $B$, Dujšin $M$, et al. Clinical and anorectal motility features in chronically constipated children. Collegium Antropologicum 2011; 35: 505-12.

38. Borowitz SM, Sutphen J, Ling W, Cox DJ. Lack of correlation of anorectal manometry with symptoms of chronic childhood constipation and encopresis. Dis Colon Rectum 1996; 39 : 400-5.

Received: 21.06 .2018

Accepted: 9.08 .2018 